\title{
Glutamine on critical-ill patients: a systematic review and meta-analysis
}

\author{
Yueming Sun ${ }^{1 \#}$, Sainan $\mathrm{Zhu}^{2 \#}$, Shuangling $\mathrm{Li}^{1}$, Hong Liu ${ }^{3}$ \\ ${ }^{1}$ Department of Critical Care Medicine, Peking University First Hospital, Beijing, China; ${ }^{2}$ Department of Biostatistics, Peking University First \\ Hospital, Beijing, China; ${ }^{3}$ Department of Critical Care Medicine, First Hospital of Shanxi Medical University, Taiyuan, China \\ Contributions: (I) Conception and design: S Li; (II) Administrative support: S Li; (III) Provision of study materials or patients: S Li, H Liu; (IV) \\ Collection and assembly of data: S Li, H Liu; (V) Data analysis and interpretation: S Zhu, Y Sun; (VI) Manuscript writing: All authors; (VII) Final \\ approval of manuscript: All authors. \\ "These authors contributed equally to this work. \\ Correspondence to: Shuangling Li. Department of Critical Care Medicine, Peking University First Hospital, Beijing 100034, China. \\ Email: lishuangling888@hotmail.com; Hong Liu. Department of Critical Care Medicine, First Hospital of Shanxi Medical University, Taiyuan, \\ China. Email: 1h9098@aliyun.com.
}

Background: To conduct a meta-analysis of the effect of glutamine supplements on prognosis in adult critical-ill patients.

Methods: We searched the Web of Science, Cochrane library, PubMed, the Wanfang Database, and the China National Knowledge Infrastructure (CNKI)/CBMdisc database. The primary outcome was hospital mortality, or if not reported, 28-day/6-month/intensive care unit (ICU) mortality. The secondary outcomes were duration of mechanical ventilation (MV), length of stay (LOS) in the ICU, LOS in the hospital, and nosocomial infections.

Results: In 599 related articles, 47 randomized controlled trials, including 6,198 patients, met all the inclusion criteria. Hospital mortality was not significantly different between the glutamine group and the control group. Length of MV was significantly higher in the control group than that of the glutamine group. In a subgroup analysis of severely burned patients, hospital mortality had the same trend. In other subgroups, there was no significant difference between the two groups.

Conclusions: We suggest that supplemental glutamine need not be routinely added to the diet of criticalill patients to reduce hospital mortality, with the exception of the diet of severely burned patients.

Keywords: Glutamine; critically ill patients; intensive care unit (ICU); nutrition

Submitted Mar 18, 2020. Accepted for publication Sep 18, 2020.

doi: 10.21037/apm-20-702

View this article at: http://dx.doi.org/10.21037/apm-20-702

\section{Introduction}

Glutamine is known as an essential nutrient for critically ill patients (1). Useful enteral nutrition products in the ICU include glutamine, a natural content of proteins. However, parenteral nutritional products do not contain glutamine due to its instable properties in aqueous solution (2-5). In the guidelines announced by the Society of Critical Care Medicine and the American Society for Parenteral and Enteral Nutrition in 2016, supplemental glutamine was not recommended for routine use in either enteral or parenteral regimens (6). However, early studies had supported enteral or parenteral glutamine supplementation in critically ill patients, as it was demonstrated that enteral administration of glutamine reduced bacterial translocation (7). Bacterial translocation and gut-origin sepsis may be involved in the pathogenesis of systemic infectious complications and multiple organ deficiency syndromes (8). In addition, clinical studies have suggested that parenteral glutamine supplementation reduced hospital mortality and new 
nosocomial infections (9-11), although some other lowquality studies showed conflicting results. Two large trials $(12,13)$ reported on glutamine supplements for critically ill patients but did not provide evidence for benefit. Ziegler et al. (14) showed that parenteral supplementation with glutamine was safe for critically ill patients, with no effect on hospital mortality, mortality at 6 months, or nosocomial infections. As such, supplying glutamine to critically ill patients remains controversial, and several clinical nutritional research studies have focused on this question in recent years. We present the following article according to the Preferred Reporting Items for Systematic Reviews and Meta-Analyses (PRISMA) reporting checklist (15) (available at http://dx.doi.org/10.21037/apm-20-702).

This study was to investigate the impact of glutamine supplementation (enteral or parenteral) on the prognosis of adult critically ill patients and patients with specific disease types (e.g., severely burned and serious acute pancreatitis) using a meta-analysis of randomized, placebo- or blankcontrolled trials.

\section{Methods}

\section{Eligibility criteria}

Trials included in this article were as follows: (I) randomized controlled groups; (II) Participants were aged 18 years or older; (III) included critically ill patients and patients with specific diseases (e.g., severely burned and serious acute pancreatitis); (IV) intervention with a parenteral or enteral glutamine supplement compared to placebo alone or no intervention; (V) articles published between 1997 and June 2017 in Chinese or English.

The primary outcome was hospital mortality, or if not reported, 28-day/6-month/ICU mortality. Secondary outcomes included duration of mechanical ventilation (MV), length of stay (LOS) in the ICU, LOS in the hospital, and nosocomial infections.

\section{Information sources}

We identified 642 records through database searching, including: Web of Science (278 articles), the Cochrane library [177], PubMed [134], the Wanfang Database/China National Knowledge Infrastructure (CNKI)/CBMdisc database [53]. After removing 43 duplicates, 599 unique records remained. Of these, 47 records were included in the final meta-analysis.

\section{Search}

The following key words were used as search terms for each English language database: "Glutamine" or "glutamine $(\mathrm{MH})$ " or "L-glutamine" and "critical care" or "critical patients" or "critical ill" or "critically ill patients" or "critical illness" or "serious illness" or "seriously ill" or "intensive care units" or "Intensive Care Units" [Mesh] or "intensive care" or "surgical intensive care unit" or "SICU" or "critical care medicine". In the Chinese database, the key words were: "Intensive care unit" or "ICU" or "zhong zheng jian hu bing fang" [Weighting:extension] or "zhong zheng jian hu shi" or "zhong zheng jian hu bing fang") and ("gu an xian an" [Weighting:extension] or "gu an xian an".

\section{Data collection}

Two reviewers (S.L.L., H.L.) independently screened the trails following the inclusion criteria. Any arguments were set down by consensus from four authors (Y.M.S., S.N.Z, H.L., S.L.L.).

After exclusion, 47 randomized controlled trials were included in the final meta-analysis. We recorded the total number of patients, number of patients in the control group and the glutamine group, hospital mortality, 28-day/6month/ICU mortality, duration of MV, LOS in the ICU, LOS in the hospital, and nosocomial infections.

\section{Risk of bias assessment}

We used the Jadad score as an assessment of the quality of individual randomized controlled trials, and the Cochrane Collaboration Risk of Bias Tool as an assessment for risk of bias. Parameters included in the Risk of Bias Tool were: (I) randomization sequence (selection bias); (II) allocation concealment (selection bias); (III) blinding of study personnel and participants (performance bias); (IV) blinding of outcome assessment (detection bias); (V) incomplete outcome data (attrition bias), (VI) selective reporting bias; (VII) other sources of bias (16). Risk of bias were assessed for sensitivity analyses and potential heterogeneity.

\section{Statistical analysis}

The primary outcome was hospital mortality. If hospital mortality was not reported, we also considered 28-day mortality, 6-month mortality, and ICU mortality. Secondary outcomes included duration of MV, LOS in the ICU, LOS in the hospital, and nosocomial infections. Data were 


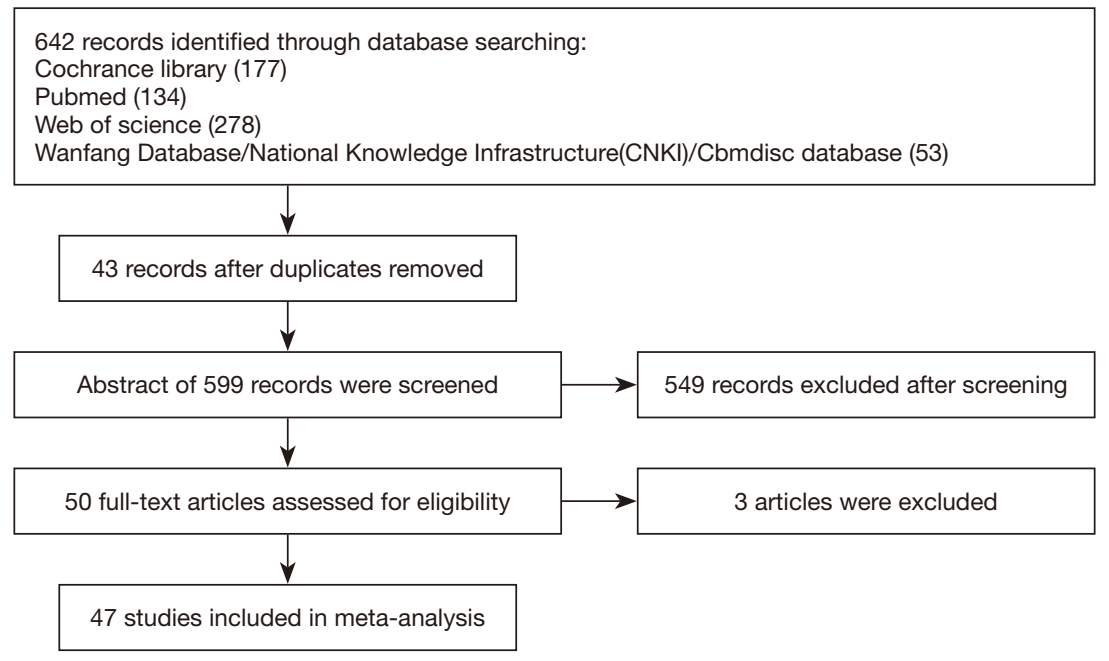

Figure 1 Flowchart of meta-analysis.

analyzed using Review Manager, version 5.3. Qualitative variables were presented as risk ratios (RRs) and $95 \%$ confidence intervals (CIs). Quantitative variables were presented as means \pm standard deviations $(\mathrm{SDs})$.

\section{Synthesis of results}

Heterogeneity was analyzed by the Mantel-Haenszel chisquare test. A P value $<0.05$ or $\mathrm{I}^{2}>50 \%$ represented obvious heterogeneity. Random effects models were used for analyses involving high heterogeneity studies, while fixed effects models were used for low heterogeneity analyses. Selective reporting bias was presented as funnel plots.

\section{Subgroup meta-analysis}

Subgroup meta-analyses were conducted to estimate the effect of glutamine supplements on specific patient populations (surgical ICU, medical ICU, or trauma ICU), specific diseases (severely burned and serious acute pancreatitis), specific dosages (below $0.3 \mathrm{~g} / \mathrm{kg} / \mathrm{day}$, between $0.3 \mathrm{~g} / \mathrm{kg} /$ day and $0.5 \mathrm{~g} / \mathrm{kg} /$ day, above $0.5 \mathrm{~g} / \mathrm{kg} /$ day), and modes of delivery (parenteral, enteral, or a combination).

\section{Results}

\section{Study location and selection}

Abstracts for 599 records were screened, and 47 records were included in the final meta-analysis, including 6,198 patients. Hospital mortality events were reported in 26 RCTs.
Mortality at 28 days was reported in 9 RCTs. Mortality at 6 months was reported in 9 RCTs. ICU mortality events were reported in 14 RCTs. A flow chart outlining the selection process for the meta-analysis is provided (Figure 1).

\section{Risk of bias}

Of all articles included in the final analysis, 11 articles were considered to be high risk of bias, 20 articles were at medium risk of bias, and 16 articles were at low risk of bias.

Across studies, there was risk of bias in the analyses of mortality at 28 days, mortality at 6 months, ICU mortality, and nosocomial infections.

\section{Summary of studies}

A total of 47 records were included in the meta-analysis comparing glutamine supplements with control in critically ill patients. Patients from 3 studies were admitted to medical ICUs, 10 to surgical ICUs, and 11 to trauma ICUs. A combined 8 studies reported on severely burned patients, and 2 studies included patients with serious acute pancreatitis. High-dose glutamine (above $0.5 \mathrm{~g} / \mathrm{kg} /$ day) was delivered to patients in 8 studies, low-dose glutamine (below $0.3 \mathrm{~g} / \mathrm{kg} /$ day) in 11 studies, medium-dose glutamine (between $0.3 \mathrm{~g} / \mathrm{kg} /$ day and $0.5 \mathrm{~g} / \mathrm{kg} / \mathrm{day}$ ) in 27 studies, and glutamine supplements at a dose of $0.2-0.4 \mathrm{~g} / \mathrm{kg} / \mathrm{day}$ in 1 study. Enteral glutamine supplementation was delivered to patients in 19 studies, parenteral glutamine supplementation in 24 studies, and a combination of enteral and parenteral 


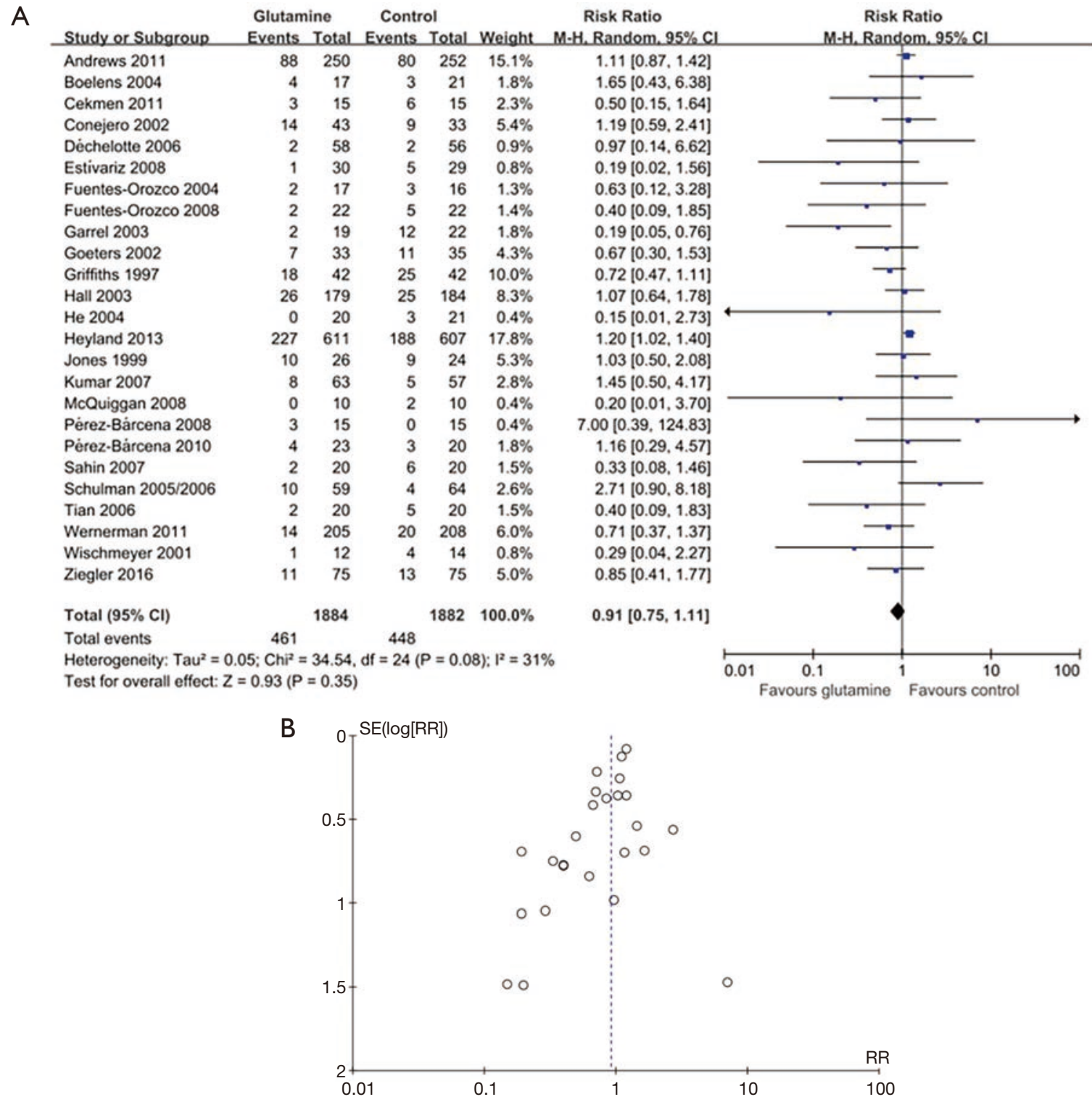

Figure 2 The effect of glutamine supplements on hospital mortality in critical-ill patients.

supplementation in 4 studies (Table S1).

\section{The impact on mortality}

\section{Hospital mortality}

There was no significant difference in hospital mortality Hospital mortality was not significantly different between control group and glutamine group (RR 0.91; 95\% CI, 0.75 to $1.11 ; \mathrm{P}=0.35$ ) (Figure 2).

We performed a subgroup analysis of the studies in accordance with glutamine dosages (below $0.3 \mathrm{~g} / \mathrm{kg} / \mathrm{day}$, between 0.3 and $0.5 \mathrm{~g} / \mathrm{kg} /$ day and above $0.5 \mathrm{~g} / \mathrm{kg} /$ day). In three subgroups, there was no significant difference in hospital mortality between control group and glutamine group (glutamine $<0.3 \mathrm{~g} / \mathrm{kg} /$ day: RR $0.88,95 \% \mathrm{CI}, 0.67$ to $1.14, \mathrm{P}=0.32 ; 0.3 \mathrm{~g} / \mathrm{kg} /$ day $\leq$ glutamine $\leq 0.5 \mathrm{~g} / \mathrm{kg} /$ day: $\mathrm{RR}$ $0.69,95 \%$ CI, 0.45 to $1.07, \mathrm{P}=0.10$; glutamine $>0.5 \mathrm{~g} / \mathrm{kg} /$ day: RR $1.18,95 \%$ CI, 0.89 to $1.54, \mathrm{P}=0.24$ ), although this was not statistically significant about the test for interaction $\mathrm{P}$ values (interaction $\mathrm{P}=0.41$ ) (Figure 3 ).

Subgroup analyses of the trials were performed according to whether the patients were in a surgical ICU, a medical 
A

Glutamine Control Risk Ratio

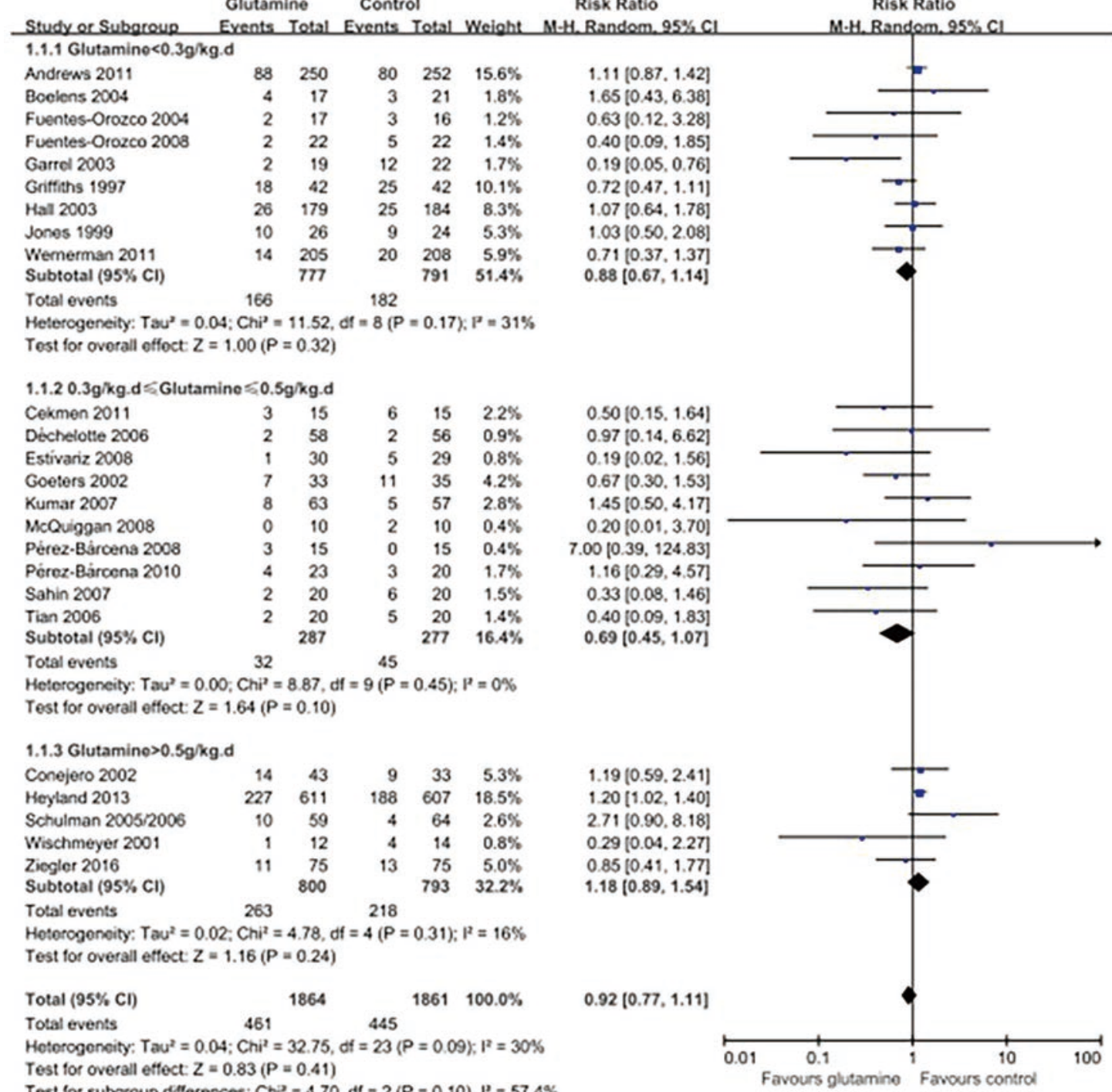

Test for subaroub differences: $C^{2}=4.70 . d f=2(P=0.10) . P=57.4 \%$

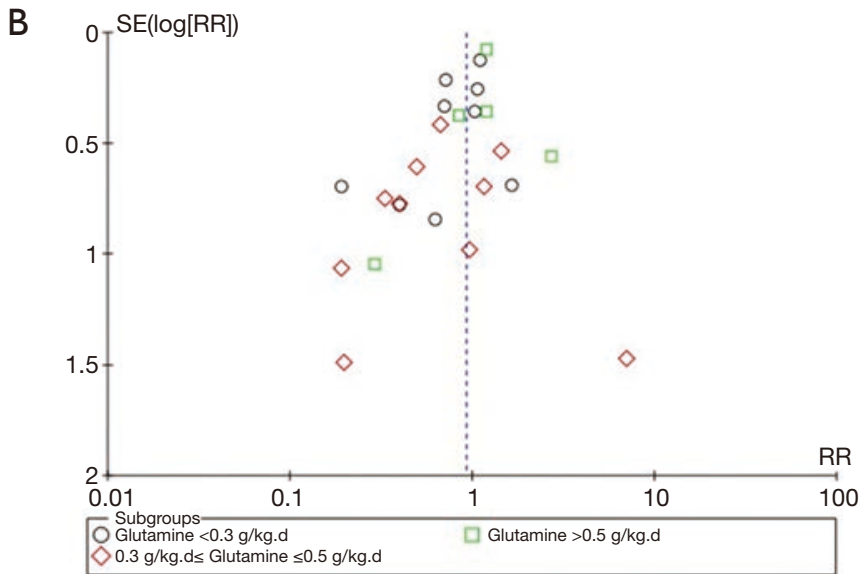

Figure 3 A subgroup of glutamine dosage for hospital mortality in critical-ill patients. 


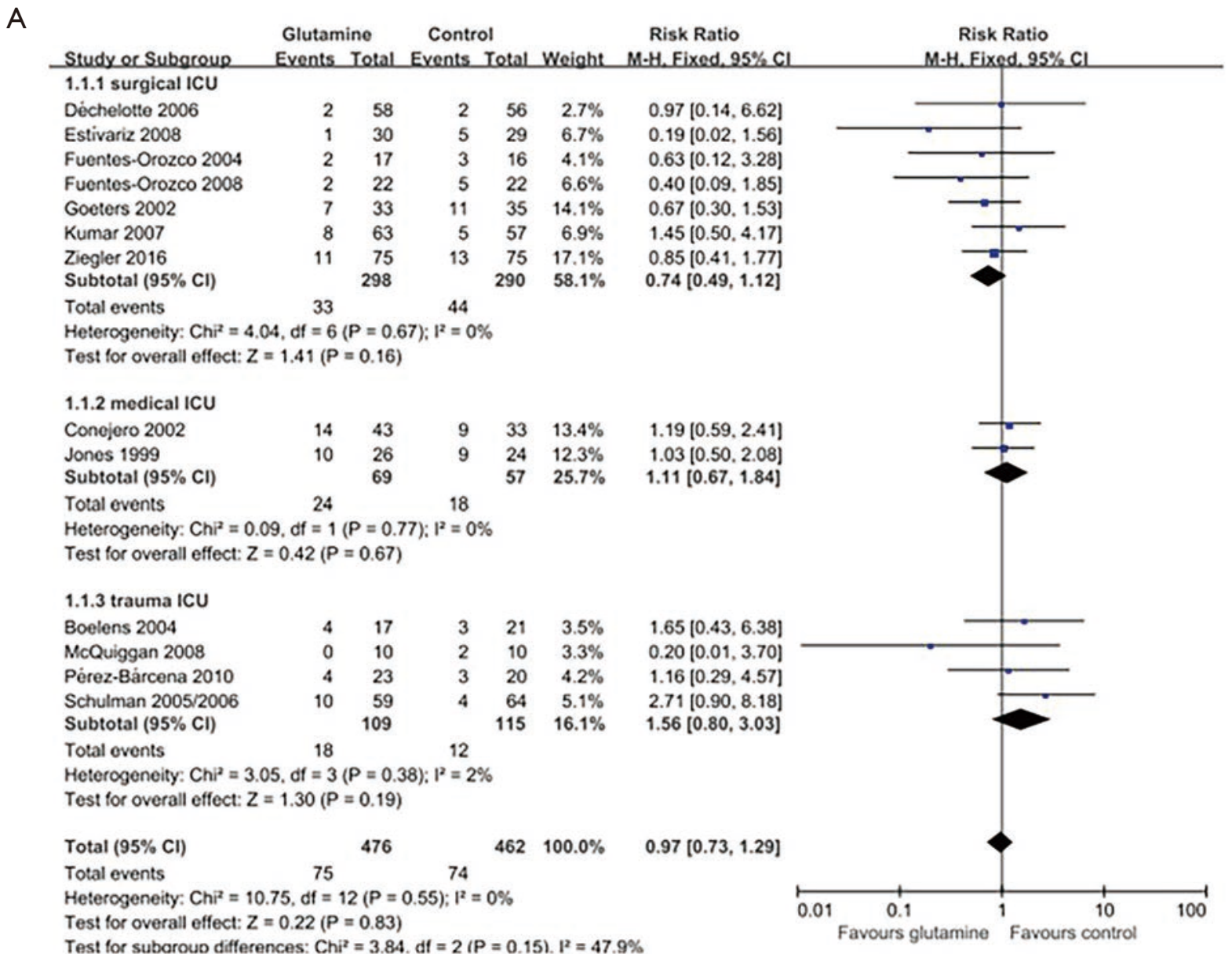

Test for subaroun differences: $\mathrm{Chi}^{2}=3.84 . \mathrm{df}=2(\mathrm{P}=0.15) . \mathrm{f}^{2}=47.9 \%$

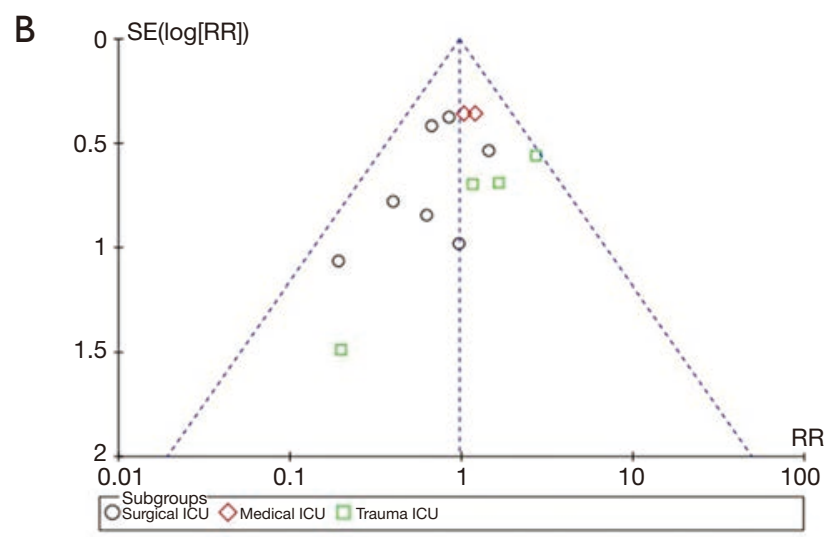

Figure 4 A subgroup of specific patient populations for hospital mortality in critical-ill patients.

ICU or a trauma ICU for glutamine on hospital mortality in specific patient populations. In three subgroups, there was no significant difference in hospital mortality between control group and glutamine group (surgical ICU: RR 0.74 , 95\% CI, 0.49 to $1.12, \mathrm{P}=0.16$; medical ICU: RR $1.11,95 \%$
CI, 0.67 to $1.84, \mathrm{P}=0.67$; trauma ICU: RR $1.56,95 \% \mathrm{CI}$, 0.80 to $3.03, \mathrm{P}=0.19$ ), although this was not statistically significant about the test for interaction $\mathrm{P}$ values (interaction $\mathrm{P}=0.83$ ) (Figure 4).

Subgroup analyses of the trials were performed according 
to enteral nutrition or parental nutrition for glutamine on different modes of nutritional supplement. In three subgroups, there was no significant difference in hospital mortality between control group and glutamine group (Pn: RR 0.80, 95\% CI, 0.62 to 1.03, P=0.09; En: RR 1.03, 95\% CI, 0.68 to $1.57, \mathrm{P}=0.89 ; \mathrm{Pn}+\mathrm{En}$ : RR $1.02,95 \% \mathrm{CI}, 0.63$ to $1.64, \mathrm{P}=0.94)$, although this was not statistically significant about the test for interaction $\mathrm{P}$ values (interaction $\mathrm{P}=0.35$ ) (Figure 5).

Subgroup analyses of the trials were performed according to patients with severely burned or serious acute pancreatitis. Hospital mortality in control group was significantly higher than that of the burn subgroup (RR 0.22; $95 \% \mathrm{CI}, 0.07$ to $0.68 ; \mathrm{P}=0.008)$. In pancreatitis subgroup, there was no significant difference in hospital mortality between the glutamine and control group (RR 0.27; 95\% CI, 0.07 to $0.99 ; \mathrm{P}=0.05)$. This was statistically significant about the test for interaction $\mathrm{P}$ values (interaction $\mathrm{P}=0.001$ ) (Figure 6).

\section{Mortality at 28 days}

Mortality at 28 days was not significantly different between control group and glutamine group (RR 1.11; 95\% CI, 0.98 to $1.24 ; \mathrm{P}=0.10$ ) (Figure 7).

Subgroup analyses of the trials were performed according to glutamine dosages for 28-day mortality of different dosages of glutamine. In three subgroups, there was no significant difference in mortality at 28 days between the control and glutamine group (glutamine $<0.3 \mathrm{~g} / \mathrm{kg} / \mathrm{day}$ : RR $1.05,95 \%$ CI, 0.88 to $1.25, \mathrm{P}=0.60 ; 0.3 \mathrm{~g} / \mathrm{kg} / \mathrm{day} \leq$ glutamine $\leq 0.5 \mathrm{~g} / \mathrm{kg} /$ day: RR $0.76,95 \% \mathrm{CI}, 0.35$ to 1.66 , $\mathrm{P}=0.49$; glutamine $>0.5 \mathrm{~g} / \mathrm{kg} /$ day: RR $1.17,95 \% \mathrm{CI}, 1.00$ to $1.38, \mathrm{P}=0.05)$, although this was not statistically significant about the test for interaction $\mathrm{P}$ values (interaction $\mathrm{P}=0.10$ ) (Figure 8).

Subgroup analyses of the trials were performed according to whether the patients were given enteral nutrition or parental nutrition for 28-mortality. In three subgroups, there was no significant difference in mortality at 28 days between patients who received enteral nutrition or parental nutrition (Pn: RR 1.05, 95\% CI, 0.88 to $1.26, \mathrm{P}=0.58$; En: RR $1.12,95 \%$ CI, 0.75 to $1.69, \mathrm{P}=0.57$; En + Pn: RR $1.14,95 \% \mathrm{CI}, 0.96$ to $1.35, \mathrm{P}=0.12$ ), although this was not statistically significant about the test for interaction $\mathrm{P}$ values (interaction $\mathrm{P}=0.10$ ) (Figure 9).

\section{Mortality at 6 months}

Mortality at 6 months was not significantly different between control group and glutamine group (RR 0.93; 95\% CI, 0.75 to $1.15 ; \mathrm{P}=0.48$ ) (Figure 10 ).

\section{Mortality in ICU}

Mortality in ICU was not significantly different between control group and glutamine group (RR 0.99; 95\% CI, 0.83 to $1.18 ; \mathrm{P}=0.92$ ) (Figure 11).

Subgroup analyses of the trials were performed according to whether the patients were in a medical ICU, a surgical ICU or a trauma ICU for glutamine on ICU mortality in specific patient populations. In three subgroups, there was no significant difference in mortality in ICU between control group and glutamine group (medical ICU: RR 0.90, $95 \%$ CI, 0.53 to $1.52, \mathrm{P}=0.69$; surgical ICU: RR $0.75,95 \%$ CI, 0.37 to $1.51, \mathrm{P}=0.42$; trauma ICU: RR $1.82,95 \% \mathrm{CI}$, 0.87 to $3.80, \mathrm{P}=0.11$ ), although this was not statistically significant about the test for interaction $\mathrm{P}$ values (interaction $\mathrm{P}=0.80$ ) (Figure 12).

\section{Secondary outcomes}

\section{Length of stay in ICU}

Length of stay in ICU was not significantly different between control group and glutamine group $(\mathrm{WMD}=$ $-0.36,95 \% \mathrm{CI},-2.18$ to $1.46, \mathrm{P}=0.70$ ) (Figure 13).

\section{Length of mechanical ventilation}

Length of $M V$ was significantly different between glutamine group and control group. Length of $\mathrm{MV}$ in the control group was significantly higher than that of the glutamine group (WMD, $-2.39 ; 95 \% \mathrm{CI},-4.09$ to $-0.68 ; \mathrm{P}=0.006$ ) (Figure 14).

\section{Length of stay in hospital}

LOS in hospital was not significantly different between control group and glutamine group (WMD, -1.92; 95\% CI, -4.82 to $0.97 ; \mathrm{P}=0.19)$ (Figure 15$)$.

\section{Nosocomial infections}

Nosocomial infections were not significantly different between control group and glutamine group (RR 0.90; 95\% CI, 0.81 to $1.01 ; \mathrm{P}=0.09$ ) (Figure 16).

\section{Discussion}

Glutamine is one of the most important antioxidants in human cells. In critically ill patients, intense immune cell activity decreased plasma glutamine concentration may be 
A

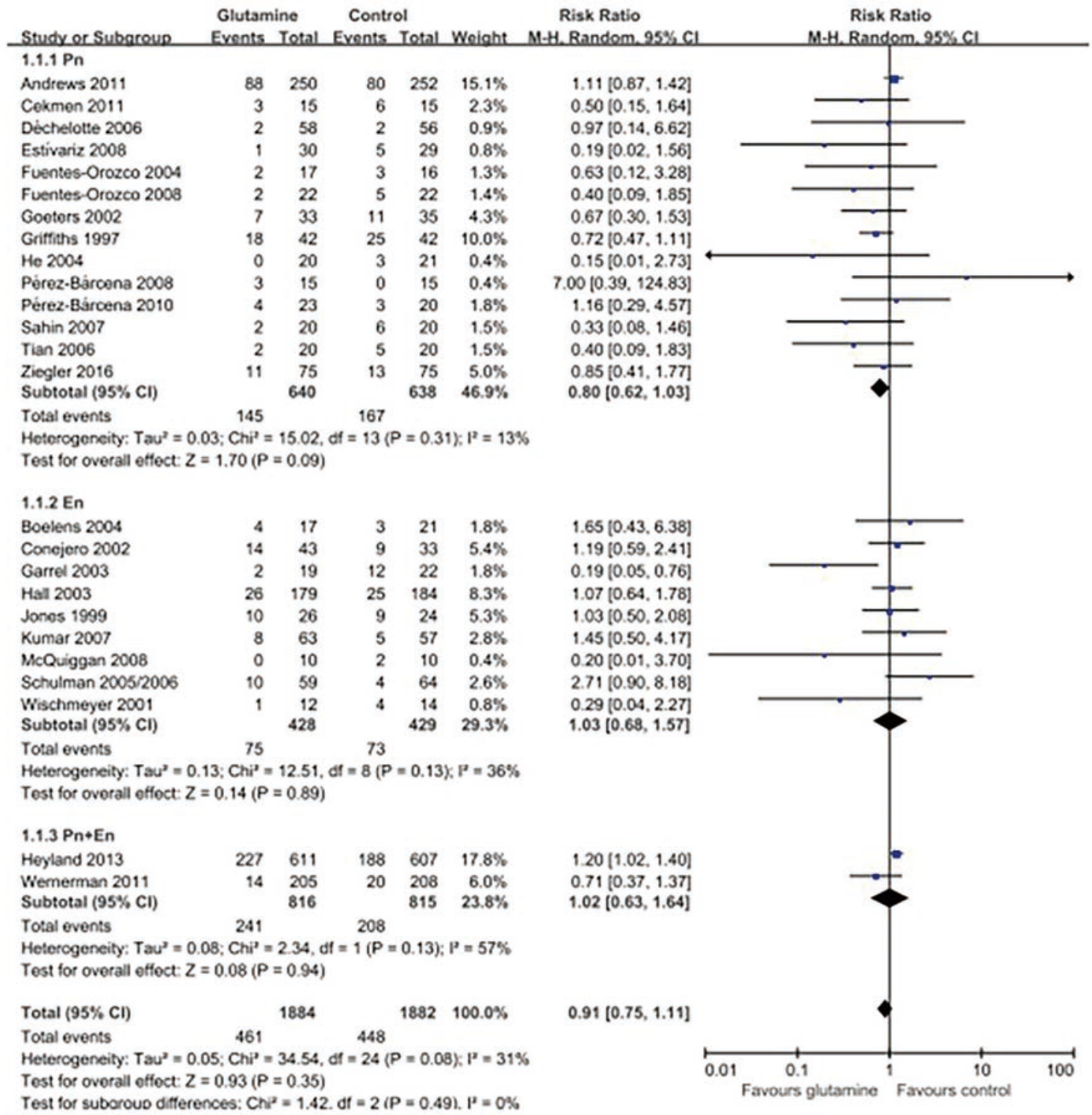

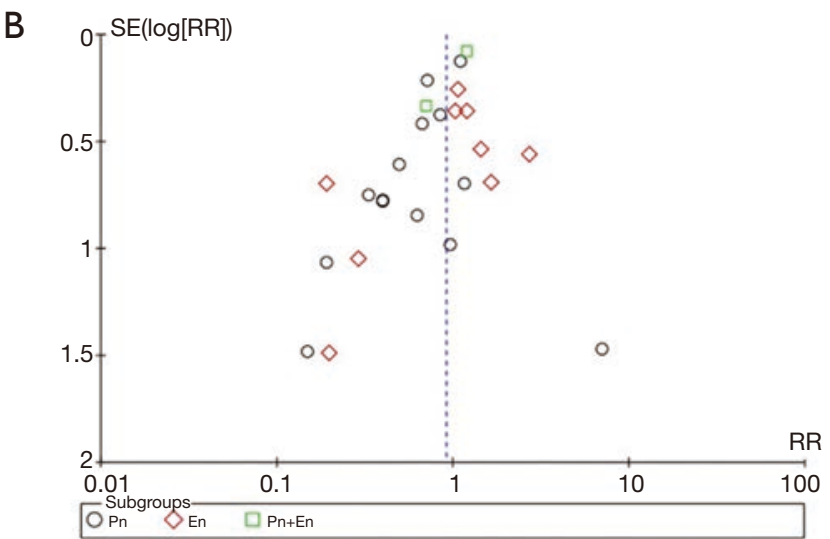

Figure 5 A subgroup of nutritional modes for hospital mortality in critical-ill patients. 

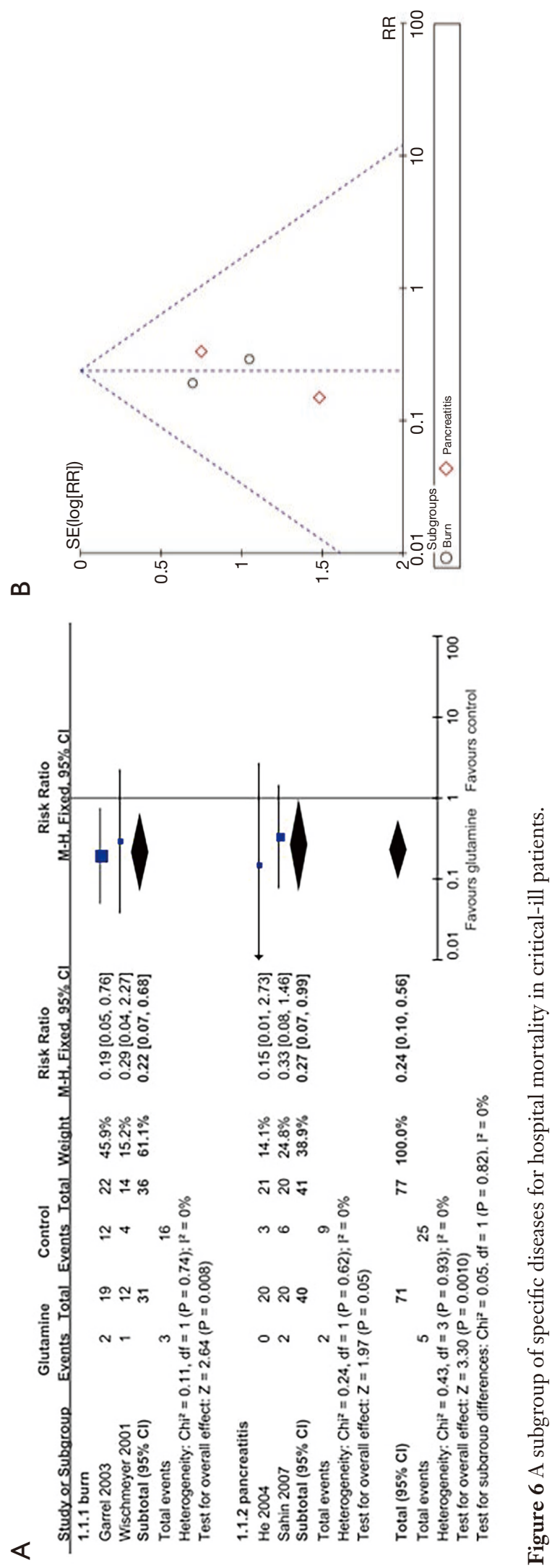

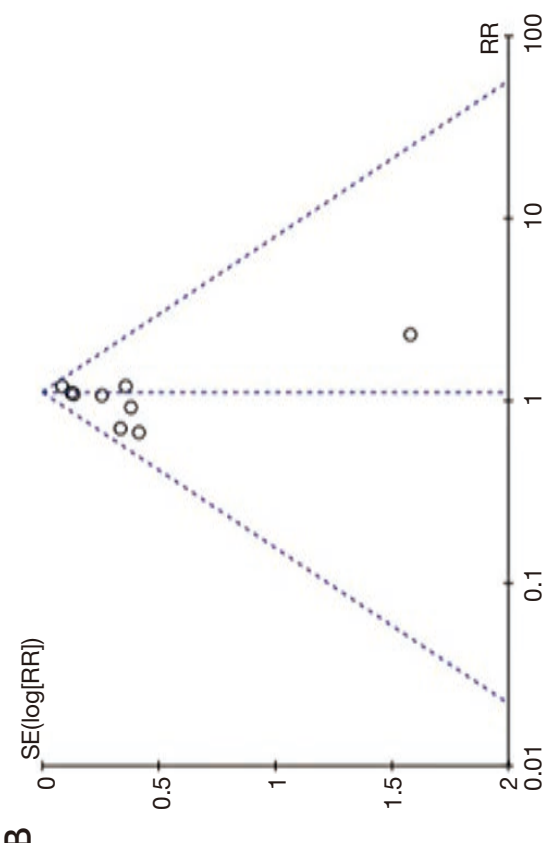

$\infty$

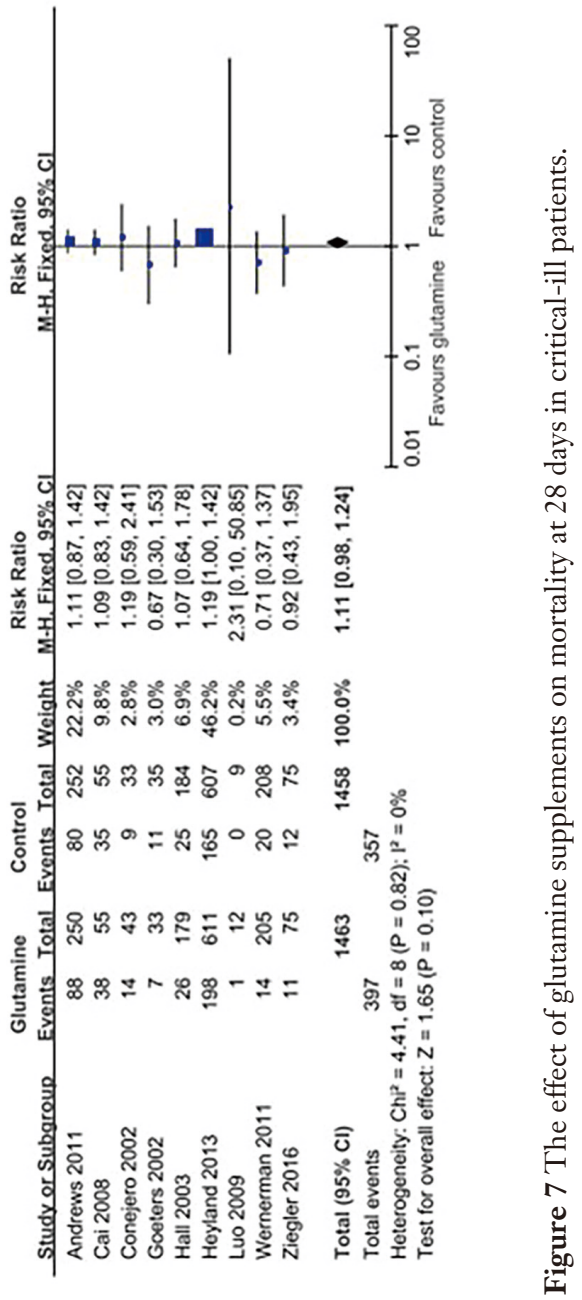


A

\begin{tabular}{|c|c|c|c|c|c|c|c|c|c|}
\hline \multirow{2}{*}{ Study or Subgroup } & \multirow{2}{*}{\multicolumn{2}{|c|}{$\begin{array}{l}\text { Glutamine } \\
\text { Events Total }\end{array}$}} & \multirow{2}{*}{\multicolumn{2}{|c|}{$\begin{array}{l}\text { Control } \\
\text { Events Total }\end{array}$}} & \multicolumn{2}{|r|}{ Risk Ratio } & \multicolumn{3}{|c|}{ Risk Ratio } \\
\hline & & & & & Weight & M.H. Fixed. $95 \% \mathrm{Cl}$ & \multirow{2}{*}{\multicolumn{3}{|c|}{ M.H. Fixed. $95 \% \mathrm{Cl}$}} \\
\hline \multicolumn{7}{|c|}{ 1.1.1 Glutamino $<0.3 \mathrm{~g} / \mathrm{kg} . \mathrm{d}$} & & & \\
\hline Andrews 2011 & 88 & 250 & 80 & 252 & $22.2 \%$ & $1.11[0.87,1.42]$ & & $\mathbf{T}$ & \\
\hline Cai 2008 & 38 & 55 & 35 & 55 & $9.8 \%$ & $1.09[0.83,1.42]$ & & $\longrightarrow$ & \\
\hline Hall 2003 & 26 & 179 & 25 & 184 & $6.9 \%$ & $1.07[0.64,1.78]$ & & & \\
\hline Wernerman 2011 & 14 & 205 & 20 & 208 & $5.5 \%$ & $0.71[0.37,1.37]$ & & t & \\
\hline Subtotal $(95 \% \mathrm{Cl})$ & & 689 & & 699 & $44.4 \%$ & $1.05[0.88,1.25]$ & & 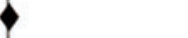 & \\
\hline \multirow{2}{*}{\multicolumn{10}{|c|}{ Heterogeneity: $C i^{2}=1.63, d f=3(P=0.65) ; P^{2}=0 \%$}} \\
\hline & & & & & & & & & \\
\hline \multicolumn{10}{|c|}{ Test for overall effect: $Z=0.52(P=0.60)$} \\
\hline \multicolumn{10}{|c|}{$1.1 .20 .3 \mathrm{~g} / \mathrm{kg} . \mathrm{d} \leqslant$ Glutamine $\leqslant 0.5 \mathrm{~g} / \mathrm{kg} . \mathrm{d}$} \\
\hline Goeters 2002 & 7 & 33 & 11 & 35 & $3.0 \%$ & $0.67[0.30 .1 .53]$ & $\rightarrow$ & $\tau$ & \\
\hline Luo 2009 & 1 & 12 & 0 & 9 & $0.2 \%$ & $2.31[0.10 .50 .85]$ & & & \\
\hline Subtotal $(95 \% \mathrm{Cl})$ & & 45 & & 44 & $3.1 \%$ & $0.76[0.35,1.66]$ & & & \\
\hline \multirow{2}{*}{\multicolumn{9}{|c|}{$\begin{array}{l}\text { Ootal events } \\
\text { Heterogeneity: } C h^{2}=0.57, d^{8}=1(P=0.45): P^{2}=0 \%\end{array}$}} & \\
\hline & & & & & & & & & \\
\hline Test for overall effect & $=0.70$ & $\mathrm{~b}=0.49$ & ) & & & & & & \\
\hline \multicolumn{10}{|c|}{ 1.1.3 Glutamine $>0.5 \mathrm{~g} / \mathrm{kg} . \mathrm{d}$} \\
\hline Conejero 2002 & 14 & 43 & 9 & 33 & $2.8 \%$ & $1.19[0.59,2.41]$ & & & \\
\hline Heyland 2013 & 198 & 611 & 165 & 607 & $46.2 \%$ & $1.19[1.00,1.42]$ & & $\mathbf{P}$ & \\
\hline Ziegler 2016 & 11 & 75 & 12 & 75 & $3.4 \%$ & $0.92[0.43,1.95]$ & & & \\
\hline Subtotal $(95 \% \mathrm{Cl})$ & & 729 & & 715 & $52.4 \%$ & $1.17[1.00,1.38]$ & & $\checkmark$ & \\
\hline \multirow{3}{*}{\multicolumn{10}{|c|}{$\begin{array}{l}\text { Heterogeneity: Chi }=0.45, d f=2(P=0.80): P^{2}=0 \% \\
\text { Test for overall effect: } Z=1.92(P=0.05)\end{array}$}} \\
\hline & & & & & & & & & \\
\hline & & & & & & & & & \\
\hline Total $(95 \% \mathrm{Cl})$ & & 1463 & & 1458 & $100.0 \%$ & $1.11[0.98,1.24]$ & & 6 & \\
\hline Total events & 397 & & 357 & & & & & & \\
\hline Heterogeneity: $\mathrm{Chi}^{2}=$ & $41, \mathrm{df}=\xi$ & $B(P=0$. & $82): 1^{2}=($ & & & & & & 00 \\
\hline Test for overall effect & $=1.65$ & $=0.10$ & 8 & & & & Favours glutamine & $\begin{array}{l}1 \\
\text { Favours control }\end{array}$ & \\
\hline
\end{tabular}

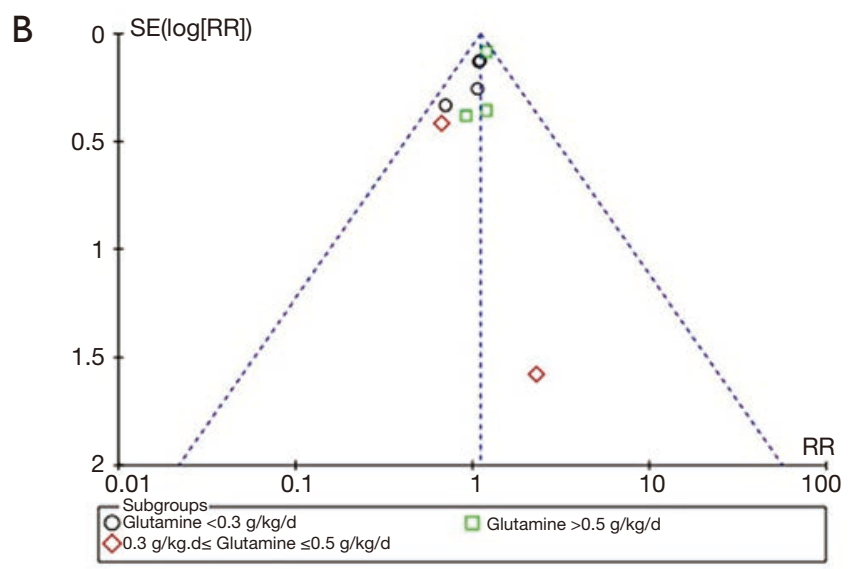

Figure 8 A subgroup of glutamine dosage for mortality at 28 days in critical-ill patients. 
A

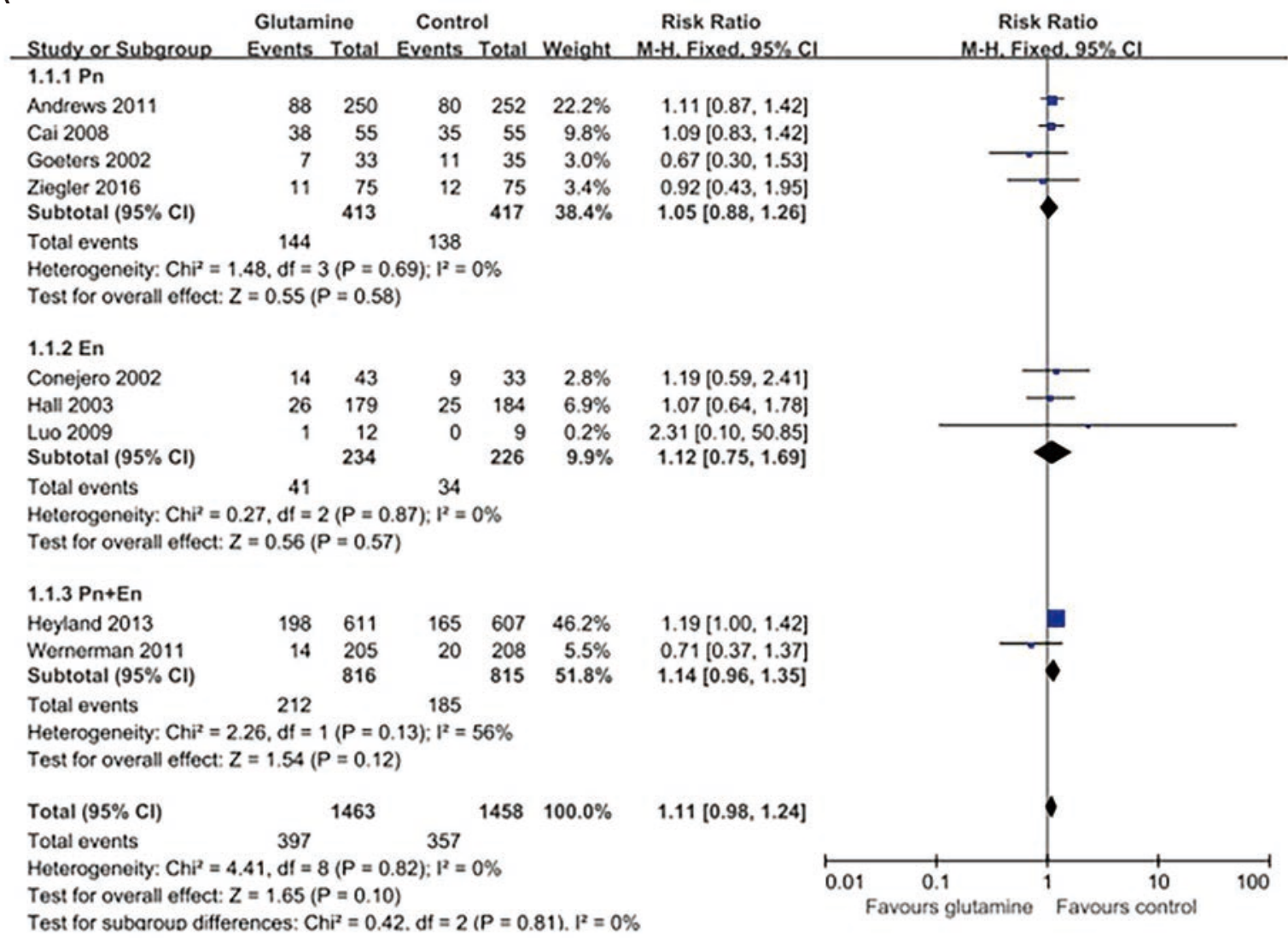

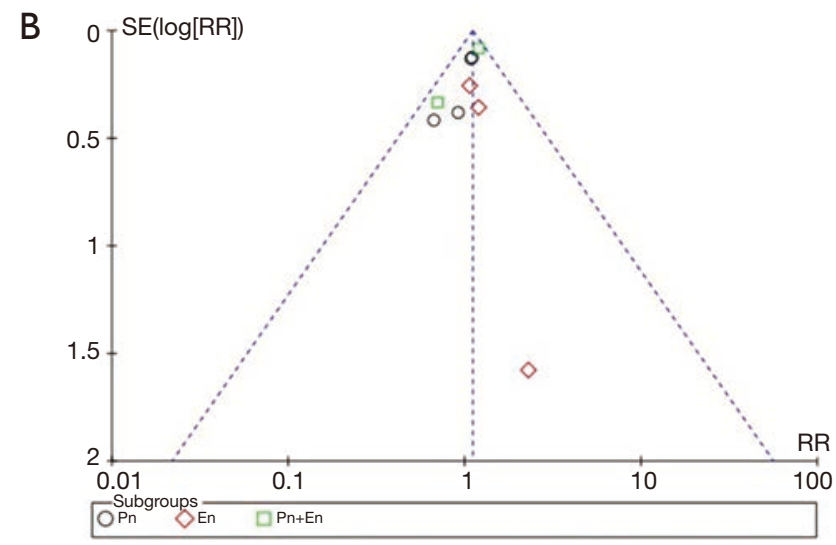

Figure 9 A subgroup of nutritional modes for mortality at 28 days in critical-ill patients. 

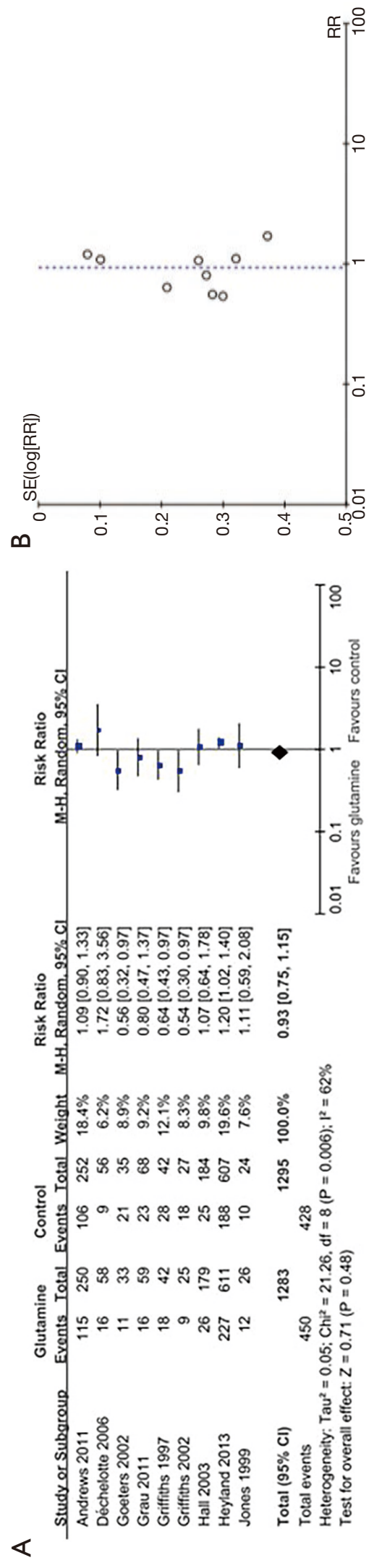
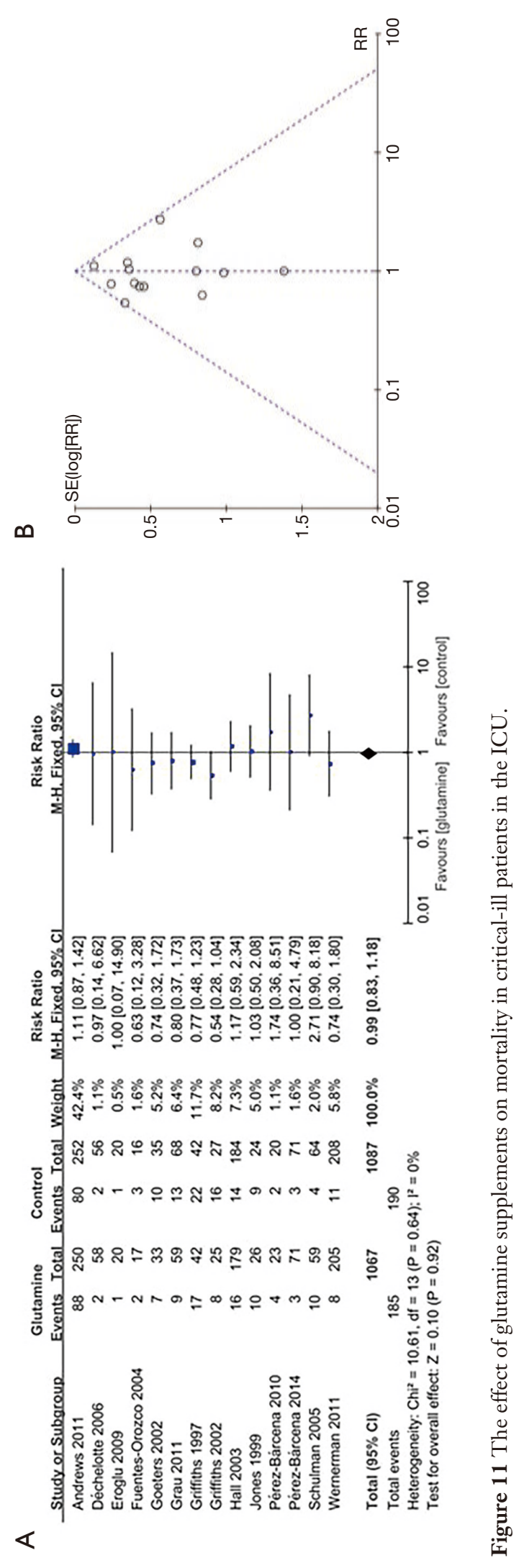
A

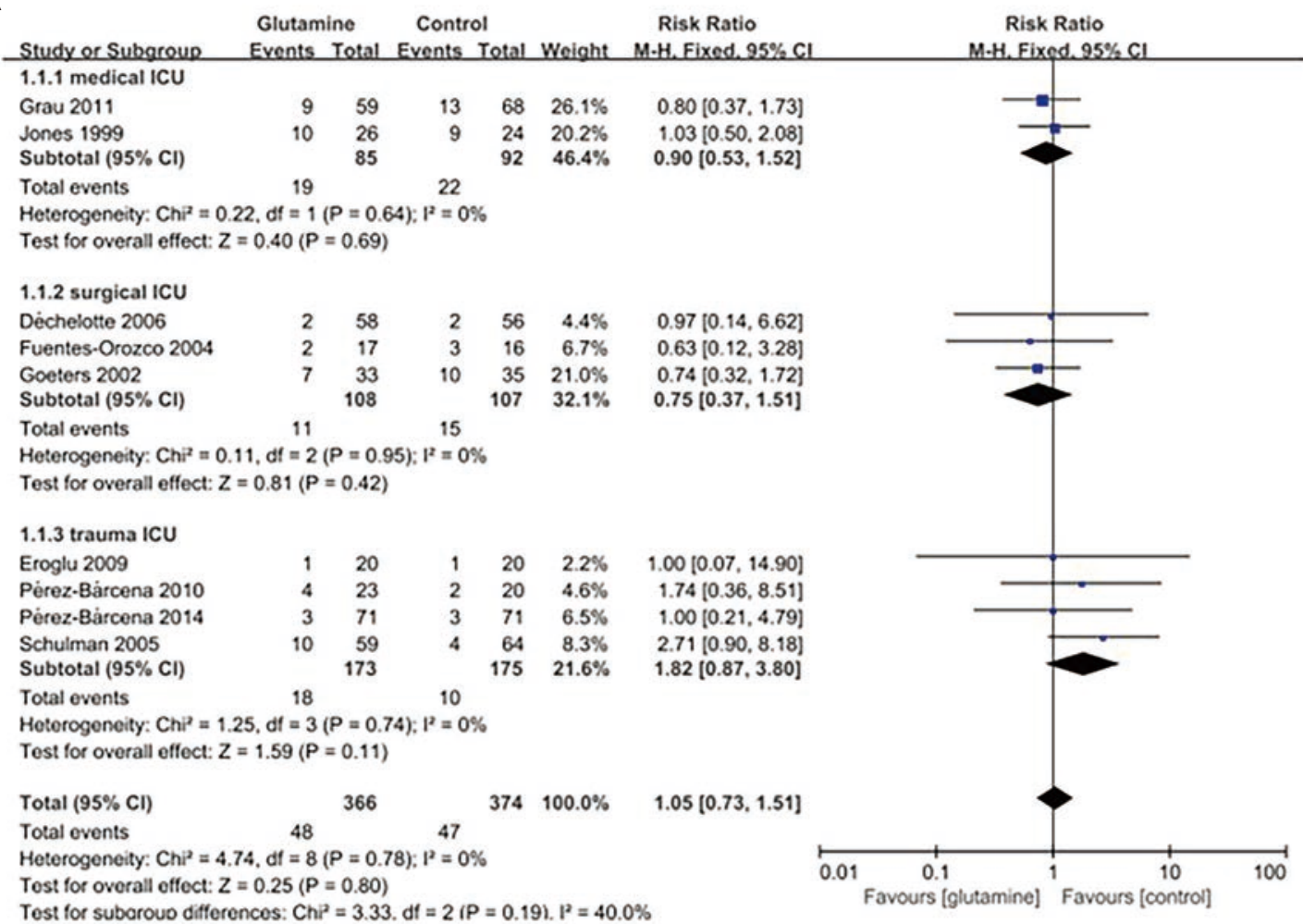

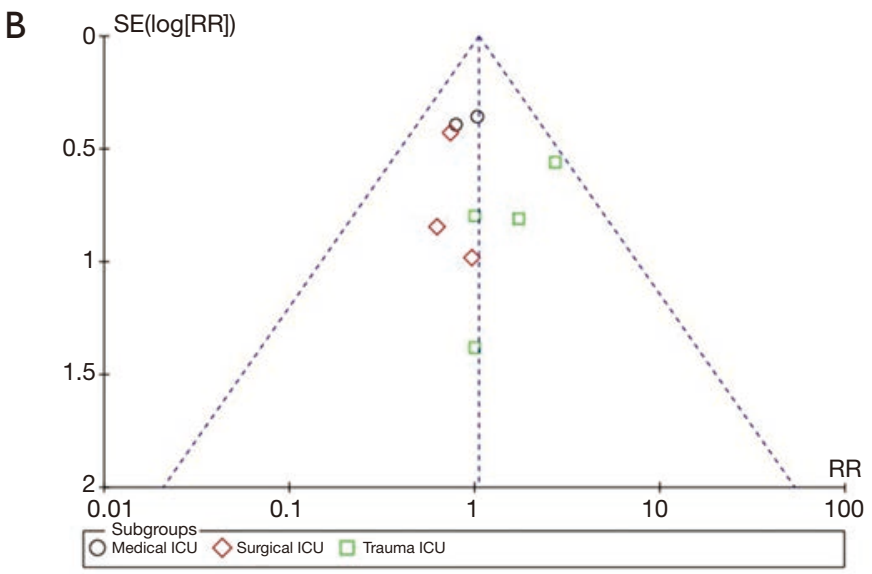

Figure 12 A subgroup of specific patient populations for mortality in the ICU. 

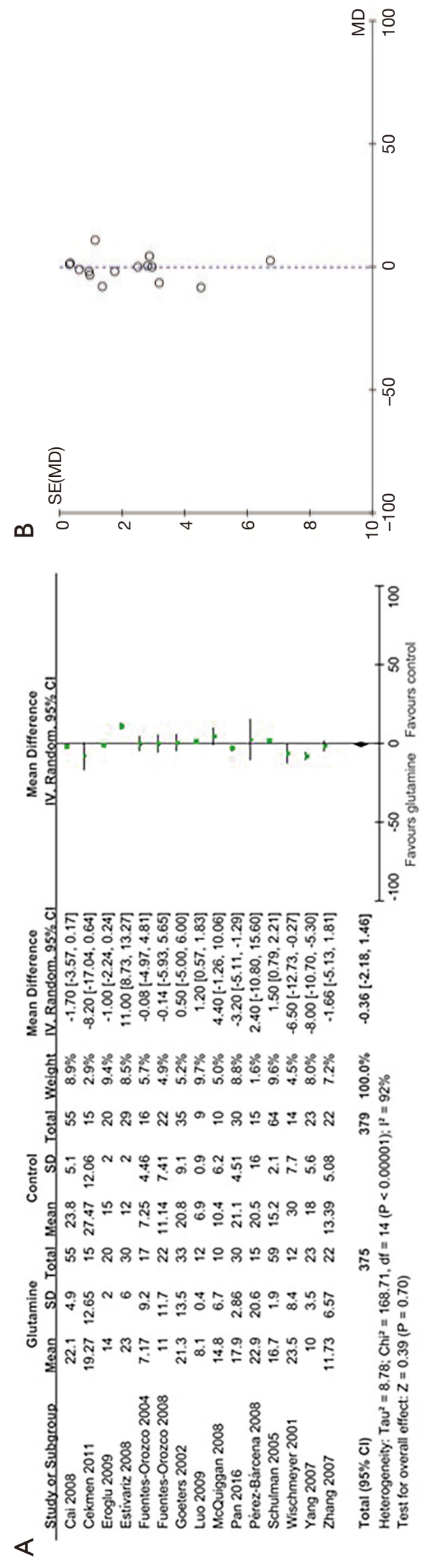
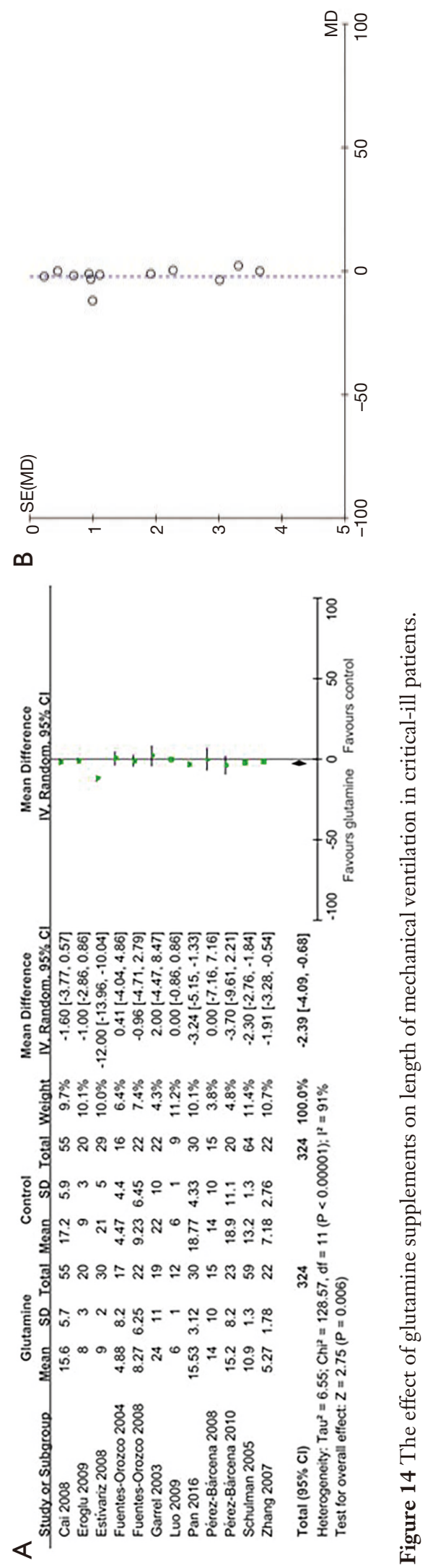

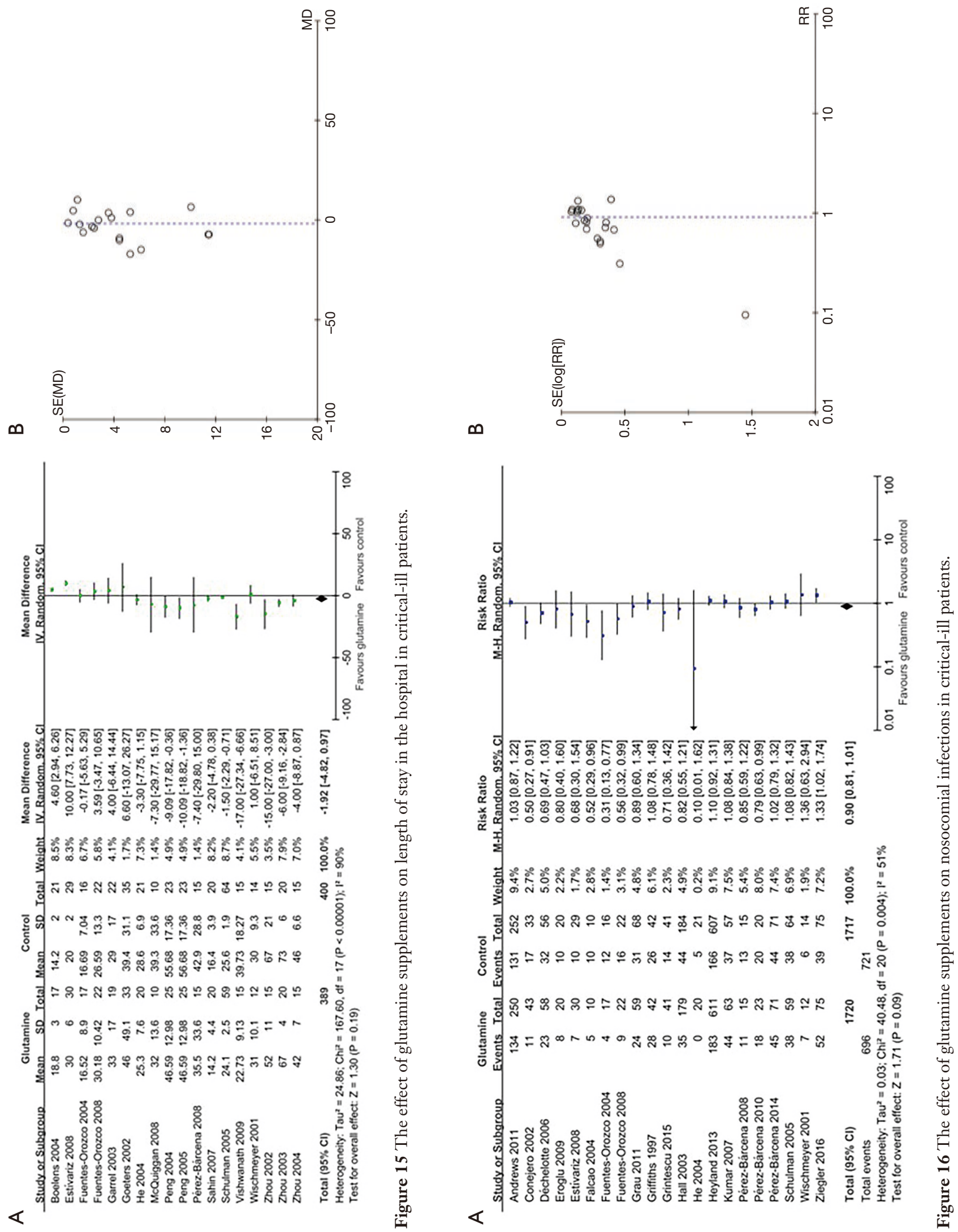
decreased. Lack of glutamine results in less expression of surface activation proteins, less production of cytokines, and induces apoptosis in these cells (17). Glutamine supplement helps to maintain its plasma level and improve prognosis in patients with critical disease conditions.

Previous meta-analyses of the effect of glutamine supplementation on mortality in critical-ill patients were not consistent. A meta-analysis showed that glutamine supplements reduced nosocomial infections in critically ill patients (18). However, Chen et al. suggested that glutamine supplements had no effect on mortality in critical-ill patients (19). Glutamine supplements had no definite effect on mortality or nosocomial infections in critically ill patients in this meta-analysis, possibly due to differences in search strategy. Another meta-analysis focused on critically ill adult patients without hepatic and/or renal failure who were haemodynamically and metabolically stabilised. The study showed that parenteral Glutamine $(0.3-0.5 \mathrm{~g} / \mathrm{kg} /$ day $)$ as part of nutrition therapy reduced reduced infectious complications, ICU LOS, hospital LOS and MV duration in critically ill patients (20). However, effects of parenteral glutamine in critically ill surgical patients were not significant (21). We found no significant difference in mortality between the control group and the glutamine group in subgroup analysis conducted to estimate the effect of glutamine supplementation on specific dosages. As such, more randomized controlled trials will be needed in the future to address this question as well.

A previous study showed that enteral glutamine supplements had no significant negative effect on gut barrier function or whole-body protein metabolism in critical-ill patients (22). A clinical study suggested that parenteral glutamine supplementation was safe in criticalill patients after surgery (14). However, Heyland et al. observed that combined enteral and parenteral glutamine supplementation increased hospital mortality and mortality at 6 months and did not decrease nosocomial infections in critically ill patients (12). Patients in that trail received the highest dose of glutamine, more than the maximal dose used in previous studies, and patients received both intravenous and enteral supplementation, whereas prior trials used either the intravenous or enteral route exclusively. Heyland et al. also targeted critically ill patients with multiorgan failure whereas previous studies typically excluded such patients. There was no significant difference in mortality between the control group and the glutamine group according to modes of nutritional supplementation; therefore, more randomized controlled trials will be needed in the future.

A previous study showed that parenteral glutamine supplements significantly decreased the length of $\mathrm{MV}$ in critical-ill patients, probably by reducing the incidence of ventilator-associated pneumonia (9). Parenteral glutamine supplements provide glutamine as a major fuel substrate for cells of the immune system. In this meta-analysis, we showed that the length of MV was significantly shorter in the glutamine group compared to the control group. However, it remains controversial whether parenteral glutamine supplementation reduces mortality in critical-ill patients. Additional large randomized controlled trials will be needed in the future to fully address this question.

Although supplemental glutamine shortened the length of $\mathrm{MV}$ in critical-ill patients, there was no effect on hospital mortality, mortality at 28 days, mortality at 6 months, or ICU mortality according to this meta-analysis. We suggest that supplemental glutamine need not be routinely delivered to critical-ill patients.

One source of infection in severely burned patients is translocation of intestinal bacteria (23-25). Enteral glutamine supplementation inhibits growth and duplication of intestinal bacteria and increases the nutrition of both intestinal epithelial cells and lymphocytes $(26,27)$. Studies have shown that glutamine supplements decreased bacteremia and hematological infections in severely burned patients and decreased mortality $(28,29)$. Wischmeyer et al. observed that glutamine supplementation induced expression of heat shock proteins and improved cell survival from endotoxin-induced septic shock (30). This metaanalysis also showed that enteral glutamine supplementation reduced hospital mortality in severely burned patients. However, glutamine supplementation had no significant effect on mortality in severe pancreatitis patients in a subgroup analysis of our study. Additional large randomized controlled trials will be needed to further address this in the future.

Some limitations of our analysis should be noted. First, we were unable to include all potentially relevant studies because we restricted our sources to those written in English or Chinese. Second, all studies included in this meta-analysis reported positive findings, and potentially unpublished negative results could not be included. Third, some of the studies included in the analysis were relatively small RCTs of lower quality. Fourth, glutamine is a nutrition. We should also consider the general nutrition therapy used including energy, essential nutrients like amino acids, fatty acids micronutrients etc. Fifth, different 
therapeutic concepts (e.g., surgical strategies, medication) may influence glutamine effects. Moreover, further study should pay attention to the total glutamine intake and the form of glutamine (in free form or as dipeptide).

\section{Conclusions}

Although supplemental glutamine shortened the length of $M V$ in critical-ill patients, there was no effect on hospital mortality, mortality at 28 days, mortality at 6 months, or ICU mortality. The effect of glutamine supplement was relatively safe for critical-ill patients. However, we suggest that supplemental glutamine need not be routinely delivered to critical-ill patients because of no effect on mortality. Following the limitations of the design, general conclusions on glutamine effects are not motivated. The supplemental glutamine should be considered for severely burned patients due to the reduced hospital mortality we observed in this patient subgroup.

\section{Acknowledgments}

The authors wish to acknowledge all the authors who performed the studies included in this work.

Funding: None.

\section{Footnote}

Reporting Checklist: The authors have completed the Preferred Reporting Items for Systematic Reviews and Meta-Analyses (PRISMA) reporting checklist. Available at http://dx.doi.org/10.21037/apm-20-702

Peer Review File: Available at http://dx.doi.org/10.21037/ apm-20-702

Conflicts of Interest: All authors have completed the ICMJE uniform disclosure form (available at http://dx.doi. org/10.21037/apm-20-702). The authors have no conflicts of interest to declare.

Ethical Statement: The authors are accountable for all aspects of the work in ensuring that questions related to the accuracy or integrity of any part of the work are appropriately investigated and resolved. All analyses were based on previous published studies, thus no ethical approval and patient consent are required.
Open Access Statement: This is an Open Access article distributed in accordance with the Creative Commons Attribution-NonCommercial-NoDerivs 4.0 International License (CC BY-NC-ND 4.0), which permits the noncommercial replication and distribution of the article with the strict proviso that no changes or edits are made and the original work is properly cited (including links to both the formal publication through the relevant DOI and the license). See: https://creativecommons.org/licenses/by-nc-nd/4.0/.

\section{References}

1. Lacey JM, Wilmore DW. Is glutamine a conditionally essential amino acid? Nutr Rev 1990;48:297-309.

2. Smedberg M, Wernerman J. Is the glutamine story over? Crit Care 2016;20:361.

3. Wischmeyer PE. Glutamine: role in critical illness and ongoing clinical trials. Curr Opin Gastroenterol 2008;24:190-7.

4. Alpers DH. Glutamine: do the data support the cause for glutamine supplementation in humans? Gastroenterology 2006;130:S106-16.

5. Labow BI, Souba WW. Glutamine. World J Surg 2000;24:1503-13.

6. McClave SA, Taylor BE, Martindale RG, et al. Guidelines for the Provision and Assessment of Nutrition Support Therapy in the Adult Critically Ill Patient: Society of Critical Care Medicine (SCCM) and American Society for Parenteral and Enteral Nutrition (A.S.P.E.N.). JPEN J Parenter Enteral Nutr 2016;40:159-211.

7. Buchman AL. Glutamine: is it a conditionally required nutrient for the human gastrointestinal system? J Am Coll Nutr 1996;15:199-205.

8. Deitch EA. Gut-origin sepsis: evolution of a concept. Surgeon 2012;10:350-6.

9. Estívariz CF, Griffith DP, Luo M, et al. Efficacy of parenteral nutrition supplemented with glutamine dipeptide to decrease hospital infections in critically ill surgical patients. JPEN J Parenter Enteral Nutr 2008;32:389-402.

10. Pérez-Bárcena J, Regueiro V, Marsé P, et al. Glutamine as a modulator of the immune system of critical care patients: effect on Toll-like receptor expression. A preliminary study. Nutrition 2008;24:522-7.

11. Fuentes-Orozco C, Cervantes-Guevara G, MuciñoHernández I, et al. L-alanyl-L-glutamine-supplemented parenteral nutrition decreases infectious morbidity rate in 
patients with severe acute pancreatitis. JPEN J Parenter Enteral Nutr 2008;32:403-11.

12. Heyland D, Muscedere J, Wischmeyer PE, et al. A randomized trial of glutamine and antioxidants in critically ill patients. N Engl J Med 2013;368:1489-97.

13. Andrews PJ, Avenell A, Noble DW, et al. Randomised trial of glutamine, selenium, or both, to supplement parenteral nutrition for critically ill patients. BMJ 2011;342:d1542.

14. Ziegler TR, May AK, Hebbar G, et al. Efficacy and Safety of Glutamine-supplemented Parenteral Nutrition in Surgical ICU Patients: An American Multicenter Randomized Controlled Trial. Ann Surg 2016;263:646-55.

15. Liberati A, Altman DG, Tetzlaff J, et al. The PRISMA statement for reporting systematic reviews and metaanalyses of studies that evaluate health care interventions: explanation and elaboration. J Clin Epidemiol 2009;62:e1-34.

16. Bollhalder L, Pfeil AM, Tomonaga Y, et al. A systematic literature review and meta-analysis of randomized clinical trials of parenteral glutamine supplementation. Clin Nutr 2013;32:213-23

17. Roth E. Nonnutritive effects of glutamine. J Nutr 2008;138:2025S-31S.

18. Corbett MS, Higgins JP, Woolacott NF. Assessing baseline imbalance in randomised trials: implications for the Cochrane risk of bias tool. Res Synth Methods 2014;5:79-85.

19. Chen QH, Yang Y, He HL, et al. The effect of glutamine therapy on outcomes in critically ill patients: a metaanalysis of randomized controlled trials. Crit Care 2014;18:R8.

20. Stehle P, Ellger B, Kojic D, et al. Glutamine dipeptidesupplemented parenteral nutrition improves the clinical outcomes of critically ill patients: A systematic evaluation of randomised controlled trials. Clin Nutr ESPEN 2017;17:75-85.

Cite this article as: Sun Y, Zhu S, Li S, Liu H. Glutamine on critical-ill patients: a systematic review and meta-analysis. Ann Palliat Med 2021;10(2):1503-1520. doi: 10.21037/apm-20-702
21. Pimentel RFW, Fernandes SL. Effects of parenteral glutamine in critically ill surgical patients: a systematic review and meta-analysis. Nutr Hosp 2020;34:616-21.

22. Luo M, Bazargan N, Griffith DP, et al. Metabolic effects of enteral versus parenteral alanyl-glutamine dipeptide administration in critically ill patients receiving enteral feeding: a pilot study. Clin Nutr 2008;27:297-306.

23. Rose JK, Herndon DN. Advances in the treatment of burn patients. Burns 1997;23 Suppl 1:S19-26.

24. Deitch EA, Rutan R, Waymack JP. Trauma, shock, and gut translocation. New Horiz 1996;4:289-99.

25. Gianotti L, Alexander JW, Pyles T, et al. Relationship between extent of burn injury and magnitude of microbial translocation from the intestine. J Burn Care Rehabil 1993;14:336-42.

26. Newsholme EA, Crabtree B, Ardawi MS. The role of high rates of glycolysis and glutamine utilization in rapidly dividing cells. Biosci Rep 1985;5:393-400.

27. Windmueller HG, Spaeth AE. Respiratory fuels and nitrogen metabolism in vivo in small intestine of fed rats. Quantitative importance of glutamine, glutamate, and aspartate. J Biol Chem 1980;255:107-12.

28. Wischmeyer PE, Lynch J, Liedel J, et al. Glutamine administration reduces Gram-negative bacteremia in severely burned patients: a prospective, randomized, double-blind trial versus isonitrogenous control. Crit Care Med 2001;29:2075-80.

29. Garrel D, Patenaude J, Nedelec B, et al. Decreased mortality and infectious morbidity in adult burn patients given enteral glutamine supplements: a prospective, controlled, randomized clinical trial. Crit Care Med 2003;31:2444-9.

30. Wischmeyer PE, Kahana M, Wolfson R, et al. Glutamine induces heat shock protein and protects against endotoxin shock in the rat. J Appl Physiol (1985) 2001;90:2403-10. 